\title{
ANALISIS STRATEGI PERUSAHAAN MULTINASIONAL PT. SHINHAN INDO FINANCE DALAM MENGEMBANGKAN BISNIS DI INDONESIA
}

\author{
Dito Kurniawan \\ Program Studi Magister Manajemen Universitas Tarumanagara \\ kurniawandito007@gmail.com
}

\begin{abstract}
Aim of this research is to analyze any strategies conducted by multinational company PT. Shinhan Indo Finance in expanding credit card business in Indonesia. This research use qualitative method whereas an interview was conducted to several departments in the company and to be compared to the theory initiated by Porter about Competitive Advantage of Nation and International Marketing Strategy. The interview has come with some results that Shinhan actually has good steps to expand the credit card business to new country but it has not been able to defeat competitors that has run the credit business since long time ago in Indonesia.
\end{abstract}

Abstrak : Tujuan penelitian ini adalah untuk melakukan analisa terhadap strategi yang dijalankan oleh perusahaan multinasional PT. Shinhan Indo Finance dalam mengembangkan bisnis kartu kredit di Indonesia. Penelitian ini menggunakan metode kualitatif dengan melakukan interview terhadap beberapa bagian didalam perusahaan lalu disandingkan dengan teori Porter mengenai Competitive Advantage of Nation dan Strategi Pemasaran Internasional. Hasil dari interview tersebut menunjukkan bahwa Shinhan sebenarnya sudah melakukan langkah yang tepat dalam perluasan bisnis namun belum mampu mengalahkan para kompetitor yang sudah menjalankan binsis kartu kredit di Indonesia sejak lama.

Keywords : multinational company, competitive advantage of nation, international marketing strategy, shinhan.

\section{PENDAHULUAN}

Sebuah perusahaan yang berasal dari Korea Selatan ingin melebarkan bisnis ke sebuah Negara berkembang di Asia Tenggara, Indonesia. Perusahaan tersebut merupakan perusahaan penerbit kartu kredit terbesar di Korea Selatan bernama Shinhan Card. Shinhan Card melakukan strategi joint venture dengan perusahaan lokal di Indonesia dalam mengembangkan bisnis kartu kredit. Shinhan Card membidik perusahaan Indomobil group sebagai sarana untuk memasarkan produk kartu kredit di Indonesia. Selain dengan jaringan Indomobil nya yang luas, Shinhan juga melihat bahwa Indomobil merupakan anak perusahaan dari grup Induk konglomerat terbesar di Indonesia, Salim Group. Pada tahun 2015, Shinhan datang ke Indonesia dan mengakuisisi saham salah satu anak perusahaan Indomobil bernama PT. Swadharma Indotama Finance sebesar 50\%+1 saham. Saat ini, perusahaan tersebut bernama PT. Shinhan Indo Finance dan mempunyai dua lini bisnis utama, pembiayaan dan kartu kredit.

Menurut Karakaya dan Kobu (1994) terdapat tiga komponen yang menyebabkan terjadinya faktor kegagalan dalam memasuki pasar. Komponen pertama adalah produk dimana design produk tidak sesuai, komponen kedua adalah masalah finansial yaitu terlalu dini meminjam hutang dalam jumlah besar dan komponen ketiga adalah masalah manajemen yakni tidak menggunakan konsep khusus dalam mengelola tim. Hal ini pun berlaku terhadap 
semua lini bisnis tidak terkecuali dalam memulai bisnis bank atau lembaga keuangan di Indonesia. Saat ini, kesulitan bank asing dalam memasuki pasar Indonesia adalah kebijakan baru pemerintah yang mewajibkan bank tersebut berbadan hukum dan berbentuk PT (Perseoran Terbatas). Dengan tujuan untuk menganalisis perusahaan asing ketika memulai bisnis di Indonesia, penelitian ini akan meneliti strategi apa yang digunakan oleh PT. Shinhan Indo Finance dalam merespon kebijakan tersebut lalu dapat sukses di pasar Indonesia. Pada tesis ini juga akan dibahas mengenai rintangan-rintangan apa saja yang dapat menghalangi perusahaan ketika memulai bisnis jasa keuangan di Indonesia.

Penelitian ini berkutat seputar bisnis di jasa keuangan -baik itu bank maupun non bank- yang mana PT. Shinhan Indo Finance mempunyai lini bisnis berupa multifinance atau pembiayaan multi-guna dan kartu kredit. Data pada penelitian ini diperoleh melalui data internal perusahaan. Dari data tersebut akan terlihat bahwa untuk memasuki pasar kartu kredit di Indonesia adalah sesuatu yang memungkinkan.

Pokok masalah yang dibahas dalam penelitian ini adalah :

- Apa strategi pemasaran Shinhan Card, selaku perusahaan penerbit kartu kredit di Korea Selatan, untuk mengembangkan bisnis ke luar negeri?

- Bagaimana budaya didalam masyarakat Indonesia mempengaruhi proses perluasan pasar dari Shinhan Card ketika memutuskan untuk melakukan Joint Venture?

- Bagaimana kesempatan dan ancaman yang dihadapi oleh PT. Shinhan Indo Finance dikelola sedemikian rupa untuk dapat sukses di pasar Indonesia?

- Bagaimana cara perusahaan mengemas produknya untuk dapat diterima di pasar Indonesia?

Penulis akan membahas beberapa isu utama dari strategi pemasaran dalam skala internasional dan beberapa isu strategi pengembangan pasar di Indonesia. Menurut Brooke dan Remmers (1978), identifikasi total atas pasar asing sangat diperlukan oleh para stakeholder perusahaan. Perusahaan yang ingin mengembangkan pasar ke Indonesia mempunyai pilihan dalam proses bisnisnya, yaitu Joint-Venture (Kotler, 1988). Joint-venture banyak dipilih oleh perusahaan asing yang ingin mengembangkan pasar di Indonesia karena itu adalah imbas dari peraturan pemerintah yang mengharuskan perusahaan mempunyai badan hukum di Indonesia. Perusahaan asing menggunakan cara ini yaitu dengan mengakuisis perusahaan lokal untuk kemudian berganti nama menjadi perusahaan asing tersebut. Akuisisi tersebut dilakukan dalam konteks perusahaan asing yang membawa beragam teknologi canggih namun tidak mempunyai pemahaman pasar yang bagus di Indonesia. Pasar yang bagus tentu saja diketahui oleh para pemain lokal yang sudah malang melintang berbisnis di Indonesia.

Menurut pendapat Benson (1975), para stakeholder perusahaan asing yang menginginkan kebebasan dalam organisasi, namun tetap mempunyai akses pada sumber daya lokal, joint-venture adalah cara yang baik dibandingkan perjanjian inter-organizational. Para stakeholder banyak berpendapat bahwa perjanjian-perjanjian dan kontrak hanya berkutat sebatas perjanjian inter-organizational dan mempunyai banyak batasan dibandingkan dengan melakukan joint venture (Berg et al., 1982; Harrigan, 1987; Killing, 1983). Menurut Berg et al, terdapat tiga alasan utama perusahaan melakukan joint venture:

- Penciptaan kekuatan pasar yang lebih besar dengan menyatukan sumber daya atau beberapa kekuatan ekonomi.

- Menjabarkan, mengurangi dan membagi informasi

- Akuisisi atau membagi informasi (Berg et al., 1992)

Alasan lainnya yang juga harus dipertimbangkan adalah:

- Untuk menghilangkan hambatan budaya, politik maupun hukum (Kent, 1991)

- Untuk memenuhi persyaratan bisnis di sebuah negara (Chu, 1987; Franko, 1973; Harrigan, 1987; UNTC, 1987) 
- Untuk mengatur persaingan di sebuah industri dengan menjadikan kompetitor sebagai teman (Bernstein, 1965; Boyle, 1968; Fusfeld, 1958; Hennart, 1988; Mead, 1973; Pleffer and Nowak, 1976).

Joint venture yang dilakukan oleh perusahaan asing di Indonesia biasanya diiringi dengan membawa teknologi dan brand dari negara asal kedalam perjanjian bisnis, dan para partner dari Indonesia menawarkan pengetahuan pasar lokal, jaringan dan sumber daya untuk membangun sebuah bisnis. Proses melakukan globalisasi oleh sebuah perusahaan dilakukan berdasarkan riset yang mumpuni. Secara teori, riset ini dilakukan berdasarkan tiga hal:

- Teori Eclectic

- Model Proses

- Jaringan Industri.

Maksud dan tujuan dari penelitian tentang strategi perusahaan dalam mengembangkan bisnis ke luar negeri adalah untuk mengetahui tingkat dari keunggulan kompetitif dari negara asal atau competitive advantage of nations. Pada lingkungan pasar kartu kredit di Indonesia, sudah banyak para kompetitor yang menawarkan banyak fitur yang disukai oleh konsumen yang ada di Indonesia. Sehingga tampaknya akan sulit bagi pendatang baru di bisnis ini untuk dapat mengalahkan para pesaing yang produknya sudah banyak disukai masyarakat Indonesia. Pendapat mengenai competitive advantage of nations ini dikemukakan oleh Porter (1990) yang banyak digunakan sebagai dasar untuk membandingkan strategi dan pendekatan yang dilakukan oleh perusahaan.

Porter mengemukakan bahwa salah satu kunci dari suksesnya suatu perusahaan dalam bersaing dengan produk lokal adalah produknya yang disukai di negara tujuan. Produk yang ada di Indonesia dan produk yang berasal dari negara Korea Selatan mempunyai pangsa produk yang sama dan bahkan untuk beberapa produk, produk dari Korea Selatan mengungguli produk asal Indonesia, smartphone misalnya. Maka dari itu, penulis menggunakan gagasan yang dikemukakan oleh Porter untuk menganalisa competitive advantage of nations yang dimiliki oleh pesaing lokal untuk dapat dikalahkan oleh produk kartu kredit Shinhan Indo. Porter (1990: 578-584) menjelaskan tentang beberapa competitive advantage of nations yang akan digunakan dalam penelitian ini:

- Competitive Advantage menumbuhkan peningkatan, inovasi dan perubahan

- Competitive Advantage melibatkan seluruh rantai nilai

- Competitive Advantage berkelanjutan melalui peningkatan tiada henti

- Peningkatan pada sektor bahan baku untuk pemenuhan kebutuhan

- Peningkatan pada sektor bahan baku untuk persaingan global

- Menjual produk kepada pelanggan yang sangat membutuhkan produknya

- Mencari kebutuhan pembeli yang sulit untuk terpenuhi

- Menetapkan peraturan untuk menembus regulasi negara tujuan yang rumit

- Memperlakukan karyawan sebagai karyawan tetap

- Menetapkan kompetitor sebagai motivasi untuk terus menciptakan produk berkualitas. Teori ini akan digunakan dalam analisa strategi PT. Shinhan Indo Finance dalam meyiapkan strategi untuk bersaing dengan para penerbit kartu kredit yang sudah ada di Indonesia. Teori ini mempunyai fungsi yang luar biasa karena menurut Porter (1991), teori ini membantu untuk mengidentifikasi beberapa variabel dan pertanyaan yang muncul untuk nanti dikembangkan menjadi strategi yang lebih baik dalam mengembangkan bisnis. Teori ini juga memiliki perhatian yang tinggi terhadap suatu masalah di perusahaan dalam mengembangkan bisnis sebelum nantinya perusahaan menyiapkan strategi untuk bersaing dengan pesaing lokal di negara tujuan. 


\section{METODE PENELITIAN}

Penulis melakukan analisa dengan menggunakan sumber data primer berupa wawancara (deep interview) dan observasi lalu data sekunder berupa studi kasus mengenai kompetitor dan telaah kepustakaan. Kedua sumber ini dapat dijelaskan sebagai berikut:

- Data Primer

Merupakan hasil dari wawancara yang dilakukan dengan beberapa stakeholder didalam perusahaan untuk menunjang bisnis kartu kredit. Tidak semua manager yang penulis wawancara, namun hanya bagian inti dari bisnis kartu kredit yang mempunyai peranan penting didalam bisinis yang dilakukan wawancara. Bagian tersebut diantaranya adalah Product Development, Risk Department, Acquisition Department dan Strategic \& Planning Department. Selain itu, terdapat beberapa data didalam lingkungan perusahaan seperti tujuan pemasaran oleh Shinhan yang akan dijadikan bahan untuk penelitian ini.

- Data Sekunder

Merupakan data yang diperoleh dari buku-buku mengenai Strategi Pemasaran Internasional oleh perusahaan asing, website para kompetitor untuk melihat bagaimana strategi yang mereka lakukan didalam mengembangkan bisnis di Indonesia dan sumber lainnya yang digunakan untuk menyiapkan tesis ini.

Pada penelitian ini, penulis memilih untuk melakukan interview dengan beberapa stakeholder didalam perusahaan, seperti para manager dan beberapa karyawan. Penulis memilih beberapa manager sebagai bahan pertimbangan untuk analisis ini seperti:

- Manager Product Development: Bpk. Mohammad Riskan;

- Manager Risk Department: Bpk. Harry Noviandry;

- Acquisition Department: Bapak Hutama Trinanda; dan

- Strategic \& Planning Department: Mr. Lee Sang Hyuk.

Serta beberapa karyawan yang dapat membantu pendapat dari para manager dalam mengemukakan jawaban pada saat proses interview. Karyawan-karyawan tersebut adalah:

- Senior Staff of Product Development: Reni Puspita Sari;

- Assistant Manager of Risk Department: Nanda Pradipta;

- Branch Manager of Acquisition Department (Kelapa Gading): Nanda Ade Prasetyo;

- Senior Assistant Manager of Strategic \& Planning Department: Sigit Dhanu Wibowo. Pemilihan karyawan-karyawan tersebut telah diseleksi karena department tersebut merupakan departemen inti dari core business perusahaan, yakni Product Development, Risk Department, Acquisition (Sales), dan Strategic dan Planning Department. Bagian Product Development merupakan bagian yang bertugas pada penciptaan produk-produk kartu kredit beserta fitur dan promosinya. Bagian Risk adalah bagian yang mengkontrol aplikasi nasabah masuk kedalam perusahaan serta melihat kapasitas akan nasabah tersebut untuk mendapatkan fasilitas kredit. Bagian Acquisition atau Sales adalah ujung tombak perusahaan dimana bagian ini mempunyai peranan penting dalam menggaet nasabah sebanyak-banyaknya. Bagian Strategic \& Plan mempunyai tanggung jawab untuk mengolah data nasabah dan melakukan laporan bulanan ke Otoritas Jasa Keuangan (OJK). Keempat bagian tersebut merupakan pemain inti dari bisnis kartu kredit di PT. Shinhan Indo Finance.

Teknik analisis yang dipilih penulis pada penelitian ini adalah kualitatif dimana banyak perumusan masalah dimulai dari interview dengan beberapa narasumber. Pendekatan jenis ini akan mempelajari isu-isu perencanaan strategi didalam perusahaan dalam mengembangkan bisnis di Negara tujuan. Metodologi yang akan digunakan dalam membuat analisis penelitian pada strategi PT. Shinhan Indo Finance dalam mengembangkan bisnis di Indonesia adalah sebagai berikut: 
- Analisa Kerangka Pemikiran Porter

Merupakan analisa dari kerangka pemikrian Porter mengenai Competitive Advante yang ditawarkan oleh Shinhan dalam menjual kartu kredit di Indonesia dengan bersandar pada hasil wawancara yang sudah dilakukan kepada beberapa manager didalam perusahaan.

- Pemasaran

Setelah analisa strategi yang dilakukan pada awal penelitian, lalu akan berlanjut pada strategi pemsaran yang diterapkan oleh perusahaan di negara tujuan. Strategi pemasaran merupakan cara perusahaan dalam meraih pangsa pasar yang tinggi di negara tujuan. Adapun analisa strategi pemasaran ini akan menitikberatkan pada beberapa hal seperti Desain Produk, Merek Produk, Positioning, Cara Periklanan dan Promosi.

\section{HASIL PENELITIAN DAN PEMBAHASAN}

Seperti yang sudah dijelaskan pada bab sebelumnya tentang konsep Porter (1990) mengenai Competitive Advantage of Nations, penulis akan menggunakan konsep/teori tersebut untuk dijadikan alat menganalisa strategi PT. Shinhan Indo Finance dalam mengembangkan bisnis di Indonesia. Analisa strategi akan dilakukan menggunakan pendekatan kualitatif yang banyak berikutat pada data dan hasil interview untuk mengetahui beberapa hal berikut:

- Competitive Advantage menumbuhkan peningkatan, inovasi dan perubahan

- Competitive Advantage melibatkan seluruh rantai nilai

- Competitive Advantage berkelanjutan melalui peningkatan tiada henti

- Peningkatan pada sektor bahan baku untuk pemenuhan kebutuhan

- Peningkatan pada sektor bahan baku untuk persaingan global

Selanjutnya, Porter berpendapat bahwa perusahaan juga harus menghadapi tekanan dan tantangan yang ada di Negara tujuan, bukan malah menghindarinya. Untuk melakukannya, Porter berpendapat bahwa perusahaan harus:

- Menjual produk kepada pelanggan yang sangat membutuhkan produknya

- Menetapkan peraturan untuk menembus regulasi negara tujuan yang rumit

- Memperlakukan karyawan sebagai karyawan tetap

- Menetapkan kompetitor sebagai motivasi untuk terus menciptakan produk berkualitas (Porter, 1990).

Nilai pertama yang dibangun oleh Shinhan adalah proses penciptaan promosi dan fitur produk. Fitur produk yang pertama kali diusung oleh Shinhan menyasar semua segmen pemegang kartu. Shinhan mempunyai tipe 4 kartu berbeda untuk ditujukan kepada semua segmen nasabah yaitu silver, gold, platinum dan infinite. Masing-masing tipe kartu ini mempunyai fitur yang berbeda satu sama lain tergantung dari segmen nasabah yang disasar. Menurut Head of Product Development, Mohammad Riskan, "Pada tahap awal Shinhan berdiri, kami akan memperkenalkan 4 kartu sebagai pondasi utama untuk menyebarkan brand Shinhan di Indonesia. 4 tipe kartu ini terdiri dari jenis silver, gold, platinum dan infinite. Untuk fitur, kami memilih fitur-fitur yang cocok disematkan berdasarkan tipe pemegang kartu. Infinte contohnya, kita memasukkan fitur keselamatan asuransi hingga sebesar 1 Millair rupiah kepada pemegang kartu. Hal ini ditujukan karena pemegang kartu infinte lebih banyak menghabiskan waktu diluar untuk urusan bisnis sehingga membutuhkan proteksi dalam setiap kegiatannya", begitu pendapat yang disampaikan terkait fitur kartu. Begitupun halnya dengan proses penciptaan promosi, dimana promosi disesuaikan dengan tipe pemegang kartu dan dibagi berdasarkan beberapa kategori. Kategori tersebut mencakup dining, entertainment, automotive dan retail market dan disesuaikan dengan tipe pemegang kartu. 
Shinhan terus melakukan peningkatan untuk mengakomodasi validitas dua data tersebut, karena di Indonesia, data seseorang sangat sulit untuk didapatkan. Belum adanya Biro Kredit Indonesia-seperti di Korea- menyulitkan para perusahaan pembiayaan untuk mendapatkan latar belakang calon nasabah ketika ingin mengajukan pinjaman. Bapak Harry Noviandry selaku division head of risk department menyampaikan pendapat terkait hal tersebut. "Dalam hal analisis kualitas nasabah, kita akan mengandalkan dua hal utama, yaitu data primer dan data sekunder. Data primer merupakan data wajib yang harus kita miliki sebelum memutuskan untuk memberikan pinjama, data tersebut berupa validitas KTP, NPWP dan slip gaji. Setelah data primer tadi, maka kita akan meminta data sekunder sebagai data penunjang, seperti data kartu kredit yang sudah dimiliki, nomor telepon kontak darurat, surat keterangan dari bagian personalia, dsb. Namun sayangnya pada data primer tersebut, masih sulit untuk dibuktikan validitasnya di Indonesia mengingat keterbatasan teknologi untuk melakukannya."

Seiring dengan keinginan melebarkan sayap ke Indonesia, perusahaan menggunakan strategi untuk meningkatkan brand image mereka kepada masyarakat Indonesia. Mr. Lee Sang Hyuk mengatakan,"Since we dedided to expand the business to Indonesia, there is one big group company to be affiliate with Shinhan Card and make the business together, Salim Group. The group will become our exclusive partner as a joint venture company to sell our credit card." Dari keterangan Mr. Lee ini, Shinhan diketahui memanfaatkan gurita bisnis Salim Group dalam hal peningkatan brand image pada saat pertama kali datang ke Indonesia. Hal tersebut juga diamini oleh Bapak Sigit Dhanu Wibowo, selaku assistant manager dari bagian strategic planning. Beliau mengatakan bahwa "Pada saat Shinhan pertama datang ke Indonesia, kita akan menggunakan database yang ada didalam perusahaan salim grup dan beberapa perusahaan korea yang ada di Indonesia untuk mulai mengenalkan kartu kredit ShinhanIndo Card. Lalu nanti langkah selanjutnya akan dijalankan melihat respon pasar yang ada.."

\section{KESIMPULAN DAN SARAN}

Strategi pemasaran Shinhan Card dalam mengembangkan bisnis di Indonesia adalah dengan melakukan akuisisi sebuah perusahaan jasa keuangan dengan jaringan yang sangat luas. Shinhan memilih Indomobil sebagai labuhan bisnis di Indonesia dan memutuskan untuk melakukan akuisisi sebesar 50\% saham anak perusahaan Indomobil ditambah 1 saham. Penambahan ini dimaksudkan agar nantinya, keputusan akhir perusahaan berada di tangan Shinhan, bukan di Indomobil. Semua proses pemasaran berada dibawah kendali Korea sehingga semua kegiatan pemasaran membutuhkan persetujuan dari Korea yang mana itu tidak begitu efektif. Konsep pemasaran yang ada di Indonesia serta di Korea memiliki perbedaan dan tidak bisa disamakan secara langsung. Korea perlu membuka diri untuk proses tersebut dan belajar mempercayai konsep yang ditawarkan oleh para manager lokal yang sudah malang melintang di bisnis kartu kredit di Indonesia.

Proses perluasan pasar yang dilakukan Shinhan Card sehingga mempunyai produk di Indonesia bernama Shinhan Indo Card mengalami beberapa kekuatan dan kelemahan. Kekuatannya adalah bahwa budaya di Indonesia mendukung perluasan pasar Shinhan ke Indonesia, apalagi dengan adanya kegiatan rutin pulang kampung tiap tahun yang mendukung penggunaan kartu kredit yang sangat tinggi. Shinhan perlu melakukan banyak promosi ketika musim pulang kampung ini tiba sehingga banyak nasabah yang menggunakan kartu ini dan angka tersebut bertambah tiap tahunnya. Selain itu, melihat kelemahan yang dihadapi tentang fraudster, pihak Shinhan harus melakukan langkah preventif baru setiap tahunnya. Karena para fraudster tersebut pasti memiliki cara baru untuk melakukan kecurangan pada sistem kartu kredit. Jika tidak ingin merugi, maka Shinhan harus terus melakukan update tentang kondisi fraudster dan menciptkan tindakan baru terkait penyalahgunaan kartu kredit. 
Kesempatan untuk mengalahkan kompetitor sangat terbuka namun pihak Korea tidak begitu mengindahkan kemampuan kompetitor di Indonesia. Hal itu disebabkan nama Shinhan yang besar di Korea sehingga tidak ingin membuka wawasan baru tentang persaingan pasar kartu kredit yang ada di Indonesia. Ancaman dari kompetitor dengan menerapkan promo menarik serta beragam fitur kartu kredit dan desain yang menarik minat nasabah tidak dijadikan pelajaran oleh Korea. Untuk sebagian besar kesempatan dan ancaman di Indonesia sudah tertutupi dengan baik, namun terdapat beberapa ancaman dari para pesaing yang belum sepenuhnya ditutupi dengan baik oleh Shinhan. Seperti dalam kerangka pemikiran Porter, bahwa produk harus dapat bersaing dengan para kompetitor serta memiliki fitur yang menarik untuk ditawarkan ke konsumen Indonesia. Oleh karena itu, untuk tahap awal penjualan kartu kredit, Shinhan masih belum mampu menunjukkan taringnya dan masih dalam tahap pengembangan ke depannya.

\section{DAFTAR PUSTAKA}

Alletzhauser, A., The house of Nomura, London: Bloomsbury, 1990.

Chisnall, P., Marketing Research, Maidenhead: McGraw-Hill Book Co, 1981.

Keegan, W.J., Global Marketing Management, Englewood Cliffs, New Jersey: Prentice Hall Inc, 1989.

Kotler, P., Marketing management, analysis, planning, implementation and control, Englewood Cliffs: Prentice Hall Inc, 1988.

Porter, M.E., The competitive advantage of nations, New York: Free Press, 1990.

Quelch, J.A. and Hoff, E.J., Customizing global marketing, Harvard Business Review, MayJune, 1986. Pp. 59-68. 
